\title{
Music in Cyberspace
}

\section{Michelle W. L. Fong, Victoria University, Melbourne, Australia}

\author{
Michelle.Fong@vu.edu.au
}

\begin{abstract}
The music scene in cyberspace is an example of how a legal framework has been developed to curb online copyright infringement. The emergence, in the mid-1990's, of online music websites and software programs such as MP3 technology to compress and download music, have delivered considerable copyright threat to the music industry. This threat has been further exacerbated by the remarkable development of technological innovations, such as high-speed broadband Internet connection and affordable CD burners, which are capable of delivering fast download and reasonably good audio and visual quality. This emerging information technology has made reproducing and sharing the work of others extremely easy, and has caused great concern for the music industry. This paper traces the evolution of the digital music scene in cyberspace and describes the attempts of the US and Australian music trade groups in putting an end to music piracy in cyberspace.
\end{abstract}

Keywords: music files, copyright, copy control, Napster.

\section{Introduction}

Prior to the 1990s, the Internet was relatively restriction-free and censorship-free because the impact of an insignificant number of users did not warrant serious concern for regulation in cyberspace. At that time, cyberspace provided a dimension of escapism from the real world, where Internet users were able to elude legal accountability for certain activities or behaviors conducted in the virtual world. As the number of Internet users and their activities increased, and as these users became more reliant on this online medium, the issue of regulating for a healthy Internet environment became a pressing concern for government and policy makers in information economies. Because the conduct of some Internet users began to show that a libertarian's use of cyberspace could generate consequences that hurt or contradicted life in the physical world, the Internet began to acquire a legal dimension with compliance requirements. In other words, there were negative externalities and misdemeanors being created and committed through the Internet that warranted a conscientious regulatory stance in cyberspace (Fong, 2003).

The music scene in cyberspace is an example of how a legal framework has been developed to curb online copyright infringement. The music companies themselves did not make their product freely accessible on the Internet, but it was their customers that upload their music into cyberspace and giving others the means to download it. The emergence, in the mid-1990's, of online music websites and software programs such as MP3 technology to compress and download mu-

Material published as part of this journal, either on-line or in print, is copyrighted by Informing Science. Permission to make digital or paper copy of part or all of these works for personal or classroom use is granted without fee provided that the copies are not made or distributed for profit or commercial advantage AND that copies 1) bear this notice in full and 2) give the full citation on the first page. It is permissible to abstract these works so long as credit is given. To copy in all other cases or to republish or to post on a server or to redistribute to lists requires specific permission from the publisher at Publisher@InformingScience.org sic, have delivered considerable copyright threat to the music industry. This threat has been further exacerbated by the remarkable development of technological innovations, such as highspeed broadband Internet connection and affordable CD burners, which are capable of delivering fast download and reasonably good audio and visual 
quality. This emerging information technology has made reproducing and sharing the work of others extremely easy, and has caused great concern for the music industry. This paper traces the evolution of the digital music scene in cyberspace and serves as preliminary groundwork for detailed research and discussion in the area.

\section{Digital Music in Cyberspace}

The case of Napster was a watershed in spelling the beginning of an end to free copyrighted music exchange and download in cyberspace. Napster was a software program that allowed Internet users to download free copies of music through the Internet. Shawn Fanning created the program in 1999, so that he could share music with a friend on campus via the Internet, and it enabled users to share and transfer songs located in their individual computers' hard drives. This peer-topeer networking feature allowed individual computers to communicate directly over the Internet, only engaging the Napster site for the index of songs to facilitate tracing and downloading of music. This method of sharing songs became popular on college campuses where many of the copyrighted songs were available for effortless download. The Napster program was easily available from the Internet and its popularity was fueled by the fact that users could download music for free through the Internet. The problem was that most of the music was protected by copyright and Napster users were sharing and exchanging it without paying. The use of this software program began to extend from campuses into households and other entertainment territorities. In addition, other similar file-sharing programs such as Gnutella and Freenet, and on-line music websites began to spring up following the popularity of Napster. The widespread exchanging and downloading of copyrighted music for free among Internet users caused grave concern in the music industry because of falling sales (Higgins, 2002). The RIAA (Recording Industry Association of America) asserted that Napster facilitated the growth of a black market for illegal copies of digital music ("Napster closure threat", 2000) and in 1999 sued the operator for copyright infringement. Music industries, Internet users, on-line music webmasters and the community worldwide closely monitored the unfolding of the legal tussle because of its implication for the future use of digital music in cyberspace. Napster staged strong resistance against the legal battle waged by the American music trade group but in July 2000 was found by the court to have acted in violation of copyright laws, and was subsequently forced to stop trading by July 28, 2000. After a reprieve and a later decision from the court restricting music distribution through its new business alliance (with Bertelsmann, a major recording company), Napster has metamorphosed from an entity offering a file-sharing program that supported free downloading of copyrighted music into one that offers Internet users a legitimate way of obtaining music as a fee-based service. The new service offers each song at US\$0.99 per download or a US\$9.95 monthly subscription for unlimited listening and downloading (Lowe, 2003; "New 'legal' Napster," 2003). To the music industry, the triumph over Napster's long-running resistance against lawsuits signifies that it can influence the technological revolution it must undergo.

Although Napster's central servers were ordered offline by the court, the distribution network that allows users to share files online was harder to close down. In addition, alternative services without centralized servers were more difficult to close down. For example, Kaaza and Gnutella have no centralized servers and do not readily provide trace to users or the files they have exchanged. Die-hard Napster users were also able to continue their downloading activities through other similar means, making detection of downloading activities more difficult to track. These included relabelling music titles with pig Latin (for example 'ollehay' instead of 'hello') or with cryptic numeric algorithms. The decentralized nature of the peer-to-peer relationship among users made the effort to eradicate online piracy more difficult because it required numerous injunctions to halt the widespread trading of content online, particularly when there were about 70 million Napster users exchanging copyrighted music for free worldwide ("New 'legal' Napster," 2003). 


\section{Strategy of the US Music Industry}

Despite the decentralized peer-to-peer network structure, the US music industry has adopted a relentless and aggressive stance in its effort to eliminate music piracy in cyberspace. Letters signed by the RIAA and two other associations from the entertainment media industry were sent to school, colleges, and big corporations, which have been major investors in high-speed technology, suggesting to these organizations that they could be liable for copyright infringement if their students or employees used their education or workplace networks to download unauthorized materials ("Bosses, ban illegal," 2002). The music industry had cause for concern, as the trend in downloading of MP3 files was popular and growing despite Napster's demise. Pew Internet and American Life Project reported that $25 \%$ of Internet users in the US downloaded music online between November and December 2000 (Pew Internet and American Life Project, 2001a). It was also found that $61 \%$ of adult Internet users who downloaded music had no regard for the copyright status of the music they retrieved online. Another survey by the same organization of children between 12 and 17 years old in the US revealed that more than half of them had downloaded music (Pew Internet and American Life Project, 2001b). This trend is on the increase and has caused great concern to the music industry as the data indicate that a whole generation could be growing up believing that music is and should be free, the view probably being nurtured by those adults who do not view illegal music downloading as serious or unacceptable. To curb the further development of such behaviour and attitudes, the RIAA has shifted its strategy from targeting file-sharing services such as Kazaa and Morpheus to a focus on individuals who have violated the Digital Millennium Copyright Act. Because of resource constraints and the difficulty involved in tracing each and every piracy offender in cyberspace, RIAA targets individuals who have shared, distributed or uploaded significant numbers of files by seeking out, for example, the one percent of Gnutella users who provided about half of the copyrighted music files for downloading and sharing (Kleiner, 2001). An amnesty program was also put in place by the music industry to let off individuals who gave an undertaking not to engage in similar behavior in the future and erased all the copyrighted music they had downloaded. On 8 September 2003, the RIAA filed 261 copyright-infringement suits in US against individuals who were suspected of copying music directly from each other through cyberspace ("Hundred sued," 2003). This lawsuit campaign launched by the RIAA communicated a message of deterrence to some violators as the incidence of music files sharing was reported to have subsequently fallen by $20 \%$ at Kazaa music-sharing sites (Soh, 2003; Brown, 2003). In a study by NPD Group Inc., it was found that about 1.4 million households in US erased all digital music files from their computers in response to threat of lawsuits or news of it. Overall, the incidence of file sharing decreased by $11 \%$ in cyberspace (Cobbs, 2003). However, some hardcore violators have simply moved to other networks to continue their activities ("Music industry settles," 2003). On the other hand, the aggressive pursuit undertaken by the RIAA against illegal file-sharing raised concerns about Internet user privacy when it coerced ISPs to reveal the identity of those individuals suspected to have breached copyright laws. For example, the US Internet provider Verizon was ordered by the US court to reveal the identity of those of customers who were suspected of illegally copying music to the US music industry under the Digital Millennium Copyright Act 1998 ("Music pirates," 2003). Privacy and free-speech advocates argued that the campaign against online copyright infringement under the subpoena provision in this Act would endanger consumers' privacy.

Although some websites involved in piracy activities were known to have shut down following threats of lawsuits or news of it, others have relocated and reopened with the same type of activities after some time ("Vivendi releases," 2002). This has presented a huge challenge and exhausting exercise for entertainment media industries in their efforts to curb online copyright infringement, and to educate Internet users that sharing music is illegal. US copyright infringement damages were normally between US $\$ 750$ and US $\$ 150,000$ per song but settlements were most common, and about half of the lawsuits were settled for an average of $\$ 3,000$ per person ("Hundreds 
sued," 2003; Cobbs, 2003). However, not every case led to a definite award of damages or settlement. While the Internet is a borderless medium, the law is not, which further aggravates the level of difficulty faced by the music industry in its attempt to combat online copyright infringement. For example, the case of Kazaa, an Australian-based company, raised a jurisdictional issue on whether the US court can enforce its ruling in cyberspace. Kazaa offers a file-swapping program like Napster, but it does not keep a central registry (or index of songs) like the latter. Kazaa was reported to have 143 million users, including previous users of the now-defunct Napster (Dray, 2003). While the Dutch courts have ruled that the users, not Kazaa, are liable if copyright is infringed, the US courts have taken a different position. In early 2003, the US courts ruled that Kazaa must respond to a lawsuit on copyright infringement filed by the RIAA, despite Kazaa's corporate citizenship and claim that it does not have substantial presence in the US. RIAA's success with Napster was hard to replicate in the case of other file-swapping networks such as Kazaa, Morpheus, Grokster and StreamCast ("Music industry settles," 2003; Black, 2003). However, RIAA's lawsuit campaign seems to have had some restrictive effect on Kazaa's new business venture, which follows legitimate procedure in its distribution of online feature films ("Kazaa to distribute," 2003).

\section{Australia}

Although doubts have been raised on its survey methodology in obtaining data, the Australian Recording Industry Association (ARIA) has estimated that 3.4 million Australians have illegally downloaded music files via file-sharing services (Varghese, 2003b; Cochrane, 2003). Compared to its US counterpart, the Australian music industry was much slower in instituting lawsuit proceedings against Internet copyright violators. However, a similar strategy was adopted in Australia whereby blatant Internet copyright violators were also targeted. On 19 November 2003, two university students were the first to face criminal prosecution for Internet music piracy in Australia. Their act of illegally uploading copyright music files onto the Internet at home was estimated by ARIA to cost at least A $\$ 60$ million ("Students get suspended terms," 2003). If this cost estimate were representative of the true population mean, the total loss to the music industry would be even higher if all copyright violators were taken into account. However, this cost estimate may well be excessive.

Actions were also taken to investigate the Internet activities of Australian university students at their learning institutions in 2003. Although Australian universities have re-written codes of Internet usage to avoid copyright infringement lawsuits, Cochrane and Miller (2003) reported that these institutions were accountable for a significant portion of music piracy traffic in cyberspace. For example, it was reported that the networks of four Australian universities located in the states of Victoria, Queensland and New South Wales accounted for 63 percent of music piracy trade (Cochrane and Miller, 2003). In February 2003, Sony, EMI and Universal applied to the Australian federal court to gain access to student email accounts of universities whose students these record companies suspected had breached copyright laws by establishing web links to sites where music can be illegally downloaded ("Web music pirates," 2003). The Federal Court granted the companies access to the universities' computer systems to investigate the allegations further. This gave rise to contentious issues, particularly in the area of whether it is the job of universities to police the Internet on behalf of the music industry, and relating to the privacy rights of Internet users.

\section{Copy Control Technology and the Law}

The quest to build copy protection into music CDs has not been entirely successful. Sony's copyprotected album launched in 2002 was reported to have damaged computers ("Singing in cyberspace," 2002). EMI has also attracted many complaints from consumers over its attempt to incor- 
porate copy control technology, which does not produce acceptable audio quality when played on a computer (Varghese, 2003a; "French court orders," 2003).

The entertainment media and software industries continue to look for foolproof technology to stop piracy. Microsoft, the biggest computer and software manufacturer, has announced its fiveyear plan to integrate copy control features into its equipment (Cochrane, 2002). It intends to install Advanced Micro Devices' chips in its product, which help to detect and prevent unauthorized content from playing on the machines. It has been envisaged that this system may even assist authorities to uncover and determine evidence of attempts to access unauthorized content.

Music and movie industries have also gone to great lengths to prevent piracy by, for example, filing lawsuits against individuals who can circumvent the copy control features in their products ("Norwegian teen acquitted," 2003; "Copy protection," 2003). This triggered concern among bona fide researchers in the US, which found that although there is an exemption under the DMCA allowing genuine researchers to study security measures and copy-prevention technology, the procedure involved in qualifying under this exemption can be convoluting and self-defeating. Researchers are required to inform the copyright holder of the intended research and disclose results before publication, which could lead to censorship and in turn, an unproductive environment for learning and research.

\section{Consumers}

One excuse for the proliferation of illegal downloading of music by some consumers was that major music labels have not been able to make digital music available at a reasonable price (Higgins, 2002; ("Vivendi releases," 2002). Despite this unusual reasoning, the widespread illegal file-sharing in cyberspace indicated to the music industry that there is a need to offer the facilities for consumers to customize their music CDs and to burn CD albums from online databases at reasonable prices. In 2003, companies such as Apple Computer Inc, Microsoft Corporate, RealNetworks Inc and BuyMusic.com launched licensed online music services that allow users to download individual songs for a minimal amount (from US $\$ 1$ each). Although such online services have yet to make a number of improvements in their product offerings, they did establish a new way of distributing music in the industry. The sales results achieved through this medium of distribution have been encouraging to the vendors. Apple Computer Inc.'s iTunes service was reported to have sold several million songs since its launch in April (Evans, 2003). Its success has attracted competitors into this online business segment and it is believed that competition forces will drive improvements in the services. In fact, buying selected music online and burning it onto CD may well make the mass-produced album of standard songs obsolete in the near future.

\section{Conclusion}

Developed music markets such as the US, UK and Australia are taking an aggressive stance in combating music piracy and exchange in cyberspace. The effort against Internet piracy has resulted in an evolution of means of access to digital music in cyberspace. In addition, this evolution has brought up issues that need to be addressed and resolved, particularly in regard to who is responsible for policing networks, the extent of ISP liability, respect for consumers' privacy, and national and international jurisdictions for compliance. Resolving these issues will take time, as they require cooperation from stakeholders at both the local and international levels.

This paper represents a preliminary effort to further research and discussion on digital music in cyberspace particularly in the areas of policies, stakeholder roles, their rights and responsibilities, and their different perspectives towards music sharing in the virtual world. 


\section{References}

Black, J. (2003, June 5). Big music: Win some, lose a lot more? Business Week Online. Retrieve on October 11, 2003 from http://0-

web20.epnet.com.library.vu.edu...9683713_AN\&print=Print\&ad=on\&ft=on\&est=

Bosses, ban illegal downloads at work. (2002, October 29). The New Paper. Retrieved on October 29, 2002 from http://newspaper.asia1.com.sg/printfriendly/0,4139,4704,00.html

Brown, K. (2003, August 4). Verizon case could set precedents. Multichannel News, 34.

Cobbs, C. (2003, November 11). Numerous central Florida Internet users may face lawsuits for music swapping. Knight Ridder Tribune Business News. Retrieved on November 13, 2003 from http://0global.factiva.com.library.vu.edu.au/en/arch/print_restults.asp

Cochrane, N. (2002, September 17). Bit by bit, digital freedom disappears. The Age. Retrieved on September 18, 2002 from http://www.theage.com.au/c...=/articles/2002/09/14/1031608343597.html

Cochrane, N. (2003, July 29). Fur to fly over file sharing. The Age. Retrieved from July 29, 2003 from http://www.theage.com.au/c.../articles/2003/07/28/1059244550640.html

Cochrane, N. and Miller, N. (2003, October 7). Universities failing to plug download pipes. The Age. Retrieved on October 11, 2003 from http://www.theage.com.au/.../articles/2003/10/06/1065292519411.html

Copy protection: company says it will not sue student. (2003, October 13). The Age. Retrieved on October 14, 2003 from http://www.theage.com.au/articles/2003/10/13/1065917318738.html

Dray, M. (2003, January 14). Australian music swap service faces swan song. The Age. Retrieved on January 14, 2003 from http://www.theage.com.au/cg...=/articles/2003/01/13/1041566442820.html

Evans, M. (2003, November 11). Music industry fights download free-for-all: Best buy. ComCast target pirates with web music services. Financial Post. Retrieved on November 11, 2003 from http://0global.factiva.com.library.vu.edu.au/en/arch/print_results.asp

Fong, M. (2003). In the Virtual World. Information Technology and Organizations: Trends, Issues, Challenges and Solution. Ed. Mehdi Khosrowpour. Hersey, USA: Idea Group Publishing. 2003 Information Resources Management Association International Conference.

French court orders EMI to refund buyer. (2003, September 4). The Age. Retrieved on September 5, 2003 from http://www.theage.com.au/articles/2003/09/04/1062548939747.html

Higgins, D. (2002, April 18). Technology aims to stop CD copies. The Age. Retrieved on April 18, 2003 from http://www.theage.com.au/articles/2002/04/17/1019020660614.html

Hundreds sued for Internet music piracy. (2003, September 9). The Age. Retrieved on September 9, 2003 from http://www.theage.com.au/articles/2003/09/09/1062902025776.html

Kazaa to distribute full-length feature film. (2003, November 14). The Age. Retrieved on November 17, 2003 from http://www.theage.com.au/articles/2003/11/14/1068674354471.html

Kleiner, K. (2001, May 7). Internet anarchy. The Age. Retrieved on May 7, 2003 from http://www.theage.com.au/news/2001/05/07/FFXC1GKODMC.html

Lowe, S. (2003, October 7). New tune for Napster. The Age. Retrieved on October 7, 2003 from http://www.theage.com.au/articles/2003/10/06/1065292529108.html

Music industry settles first case - with 12-year-old. (2003, September 10). The Age. Retrieved on September 10, 2003 from http://www.theage.com.au/articles/2003/09/10/1062902092627.html

Music pirates facing big fight with New Net police. (2003, January 27). The Age. Retrieved on January 27 , 2003 from http://www.theage.com.au/cg...=/articles/2003/01/27/1043533997340.html

Napster closure threat. (2000). BBC News. Retrieved on May 25, 2001 from

htpp://news.bbc.co.uk/hi/English/business/newsid_789000/789132.stm 
New 'legal' Napster launch this month. (2003, October 10). The Age. Retrieved on October 10, 2003 from http://www.theage.com.au/C.../articles/2003/10/10/1065676130983.html

Norwegian teen acquitted in DVD cracking case. (2003, August 1). The Age. Retrieved on January 1, 2003 from http://www.theage.com.au/cg...=/articles/2003/01/08/1041566442820.html/

Pew Internet and American Life Project. (2001a). Internet Activities. Retrieved on August 8, 2001 from http://www.pewinternet.org/reports/chart.asp?img=6_internet_activities.jpg

Pew Internet and American Life Project. (2001b). The music downloading deluge. Retrieved on April 24, 2001 from http://www.pewinternet.org/

Singing in cyberspace. (2002, November 15). The Age. Retrieved on November 15, 2003 from http://www.theage.com.au/cgi...=/articles/2002/11/14/1037080847519.html

Soh, N. (2003, August 4). Music file-swoppers in Singapore, take note. Strait Times.

Students get suspended terms in music piracy case. (2003, November 18). The Age. Retrieved on November 18, 2003 from http://www.theage.com.au/articles/2003/11/18/1069027100496.html

Varghese, S. (2003a, August 6). Copy control: is the consumer being told the whole tale? The Age. Retrieved on September 5, 2003 from http://www.theage.com.au/articles/2003/08/06/1060145711636.html

Varghese, S. (2003b, July 29). "No current plans to sue Australian file sharers: ARIA". The Age. Retrieved from July 30, 2003 from http://www.theage.com.au/c/.../articles/2003/07/29/1059244606289.html

Vivendi releases 43,000 songs on web. (2002, November 21). The Age. Retrieved on November 21, 2002 from http://www.theage.com.au/cgi...=/articles/2002/11/21/1037697787174.html

Web music pirates sentenced. (2003, November 19). The Age. Retrieved on November 19, 2003 from http://www.theage.com.au/c.../articles/2003/11/18/1069027122452.html

\section{Biography}

Michelle W. L. Fong is a lecturer in the School of Applied Economics, Victoria University. Her research interest includes information technology applications and business systems. 